Erratum zu

\title{
Awareness \\ Stellenwert des Neuromonitorings von Analgesie und Hypnose
}

Matthias J. Posch • Jan H. Baars

In Ausgabe AINS 1/13 wurde unter der Rubrik Fachwissen Anästhesiologie Topthema: Awareness der Name des Autors Bosch, Matthias J falsch angegeben - der Autor heißt richtig Posch, Matthias J. Dies wurde im Originalartikel korrigiert. 